\title{
Fatigue crack growth in SiC particle reinforced Al alloy matrix composites at high and low $R$-ratios by in situ $\mathrm{X}$-ray synchrotron tomography
}

\author{
Peter Hruby ${ }^{\mathrm{a}}$, Sudhanshu S. Singh ${ }^{\mathrm{a}}$, Jason J. Williams ${ }^{\mathrm{a}}$, Xianghui Xiao ${ }^{\mathrm{b}}$, Francesco De Carlo ${ }^{\mathrm{b}}$, \\ Nikhilesh Chawla ${ }^{\text {a,* }}$ \\ a School for Engineering of Matter, Transport, and Energy, Ira A. Fulton Schools of Engineering, Arizona State University, Tempe, AZ 85287-6106, United States \\ ${ }^{\mathrm{b}}$ Advanced Photon Source, Argonne National Laboratory, Argonne, IL, United States
}

\section{A R T I C L E I N F O}

\section{Article history:}

Received 3 February 2014

Received in revised form 7 May 2014

Accepted 22 May 2014

Available online $\mathrm{xxxx}$

\section{Keywords:}

Metal-matrix composites (MMCs)

$\mathrm{SiC}$ particles

Fatigue

$R$-ratio

X-ray tomography

\begin{abstract}
A B S T R A C T
Metal matrix composites (MMCs) offer high strength, high stiffness, low density, and good fatigue resistance, while maintaining cost an acceptable level. Fatigue resistance of MMCs depends on many aspects of composite microstructure. Fatigue crack growth behavior is particularly dependent on the reinforcement characteristics and matrix microstructure. The goal of this work is to obtain a fundamental understanding of fatigue crack growth behavior in SiC particle-reinforced $2080 \mathrm{Al}$ alloy composites. 'In situ X-ray synchrotron tomography was performed on two samples at low $(R=0.1)$ and at high $(R=0.6) R$-ratios. The resulting reconstructed images were used to obtain three-dimensional (3D) rendering of the particles and fatigue crack. Behaviors of the particles and crack, as well as their interaction, were analyzed and quantified. Four-dimensional (4D) visual representations were constructed to aid in the overall understanding of damage evolution.
\end{abstract}

(c) 2014 Elsevier Ltd. All rights reserved.

\section{Introduction}

Metal matrix composites (MMCs), composed of a light alloy matrix, such as aluminum alloy, reinforced with ceramic particulates, have a combination of high strength, high stiffness, and low density [1]. Furthermore, MMCs exhibit improved fatigue resistance over monolithic alloys. This fatigue resistance depends on a variety of factors, such as reinforcement particle volume fraction, particle size, matrix and interfacial microstructure, processinginduced inclusions or defects, and testing environment [2-8].

In previous years, an understanding of the precise nature of damage mechanisms in MMCs has been largely limited to examinations of two-dimensional (2D) fracture surfaces or polished cross-sections of the material. These techniques are laborious and restrictive due to the 2D nature of the analysis. Accurately sampling a representative volume of the microstructure by such methods is also difficult. While these surface techniques provide information about microstructure, both the microstructure and state of stress can differ greatly between the surface and the bulk $[9,10]$.

\footnotetext{
* Corresponding author. Tel.: +1 480965 2402; fax: +1 4807279321

E-mail address: nchawla@asu.edu (N. Chawla).
}

Three dimensional (3D) characterization tools have been recently developed to allow for clear, accurate, and quantitative depictions of the damage behavior of MMCs. A number of techniques have been used for the 3D visualization of MMC microstructures, including serial sectioning techniques using either mechanical polishing coupled with optical microscopy $[11,12]$ or focused ion beam milling and image reconstruction [13-15]. Although serial sectioning is a powerful technique for virtual 3D microstructure generation, it is both time consuming and destructive.

$\mathrm{X}$-ray tomography is an excellent technique that, unlike serial sectioning, is non-destructive and allows for large volumes to be studied with minimal sample preparation, resulting in statistically significant information and relatively large-scale visualization capabilities [16-19]. 3D visualization and quantification of heterogeneous microstructures has been successfully performed in Sn-rich alloys [20], powder metallurgy steels [21], metal matrix composites [22-25] and aluminum and copper alloys [26-28].

Synchrotron radiation has been used for X-ray tomography [22] and holotomography $[23,24]$ of MMCs to visualize their microstructures. SiC particle reinforced aluminum alloy matrix composites have been investigated using X-ray synchrotron tomography to visualize and quantify Fe-rich inclusions and porosity [25] as 
well as the influence of particle size and aspect ratio on tensile fracture [29]. More recently, in situ, or 4D experiments (the fourth dimension here is time) have been conducted to understand the deformation behavior in real-time. Tensile damage behavior of $\mathrm{SiC}$ particle reinforced aluminum alloy matrix has been studied using in situ X-ray synchrotron tomography [30]. In situ X-ray synchrotron tomography has been used for 3D observation and quantification of fatigue cracking in $\mathrm{Al}-\mathrm{Mg}-\mathrm{Si}$ alloys [31] and to visualize void volume changes due to thermal fatigue damage in $\mathrm{SiC}$ particle reinforced aluminum [32].

Adequate visualization and fracture quantification is critical to the understanding of damage in MMCs. Additionally, a significant amount of statistical characterization and analysis, on features such as particle fracture and crack growth, is required both before and after deformation. In situ techniques are particularly well suited for examining the initiation and evolution of damage in MMCs over time, allowing for a sound understanding of the sequence of particle fracture and crack growth during fatigue to be obtained.

In the area of fatigue, a significant amount of work has been done in trying to understand the interaction between the fatigue crack and the SiC particles [33,34]. Although the effect of load ratio (positive $R$-ratio) on fatigue crack growth behavior in MMCs has been investigated [35-37], the precise mechanisms of crack growth as a function of $R$-ratio remain poorly understood. This is partially because most fatigue crack growth studies are limited to predominantly low $R$-ratios. Moreover, the scope of existing studies at high $R$-ratios are limited to optical imaging of cracking at the sample surface and of fracture surfaces [38,39]. At low $R$-ratio crack deflection around $\mathrm{SiC}$ particles has been qualitatively shown. At high $R$-ratio, however, the key question is whether the SiC particles crack ahead of the main crack, or whether the fatigue crack grows through the originally intact SiC particles. Postmortem analysis on the surface of the specimen only shows the final state of fracture, i.e., that the crack has gone through the particle, but it does not account for potential fractures ahead of the crack tip. The precise mechanisms for fracture, not only on the surface but through the thickness, can only be verified by in situ X-ray microtomography.

In this work, the fatigue behavior of particle reinforced aluminum alloys at a high $R$-ratio (0.6) is compared to that at low $R$-ratio $(0.1)$ by in situ X-ray synchrotron tomography. In particular, the goal of this work is to obtain a fundamental understanding of how the fatigue crack interacts with SiC particles, and the role of particle fracture, both ahead of and at the crack tip, in controlling fatigue crack propagation. This behavior for high $R$-ratios versus low $R$-ratios will be discussed after quantitative analysis through $3 \mathrm{D}$ visualization of segmented particles and crack coupled with the examination of numerous 2D slices.

\section{Material and experimental procedure}

The material used in this study was a 2080 aluminum alloy (3.6\% $\mathrm{Cu}, 1.9 \% \mathrm{Mg}, 0.25 \% \mathrm{Zr}$ ) reinforced with 20 vol.\% SiC particles (average particle size of $25 \mu \mathrm{m}$ ). The materials were processed by blending $\mathrm{SiC}$ and $\mathrm{Al}$ powders, compaction of the powder mixture, hot pressing, and hot extrusion (Alcoa Inc., Alcoa, PA). Details of the powder metallurgy process for fabrication of these composite materials can be found elsewhere [5].

Fatigue crack growth experiments were carried out on single edge notched (SEN) specimens. The specimens were machined by electrical discharge machining (EDM) parallel to the extrusion axis with the crack growing normal to the extrusion axis, i.e., in the short transverse axis (L-S orientation). The specimens were approximately $1 \mathrm{~mm}$ thick, $2.7 \mathrm{~mm}$ wide, and $15 \mathrm{~mm}$ long, as shown in Fig. 1(a). A microforce testing system (MTS Tytron 250) was used to perform pre-cracking ex situ in tension-tension fatigue at the same load ratios as those used during the in situ experiment for each sample (frequency of $4 \mathrm{~Hz}, \Delta K \approx 5 \mathrm{MPa} \sqrt{ } \mathrm{m}$ ). The resulting pre-crack length for the sample tested under $R=0.1$ was $0.95 \mathrm{~mm}$, while that for $R=0.6$ was $0.55 \mathrm{~mm}$.

The fatigue experiments were performed at the Advanced Photon Source (APS) at Argonne National Laboratory under load ratios of 0.1 and 0.6 , at a frequency of $1 \mathrm{~Hz}$, using a sinusoidal waveform. X-ray synchrotron tomography was performed at the 2 BM beamline of the APS. Details of the APS beamline 2-BM have been described elsewhere [29,40-42]. Using the standard detector, a $2016 \times 2016$ pixel PCO Dimax CMOS camera coupled with a LuAG:Ce scintillator screen (used to convert the X-rays to visible light), typical exposure times of $250 \mathrm{~ms}$ per projection were obtained. In this configuration, a projection was collected every $1 / 8^{\circ}$ for $180^{\circ}$. The voxel size for $R=0.6$ experiments was $1.47 \mu \mathrm{m}$ and for $R=0.1$ was $1.8 \mu \mathrm{m}$. The tomography at one time step can be completed in about $10-15 \mathrm{~min}$. The two-dimensional (2D) projections were reconstructed in 3D using a filtered back-projection algorithm.

A specially designed loading stage, depicted in Fig. 1(b), was used for the in situ tomography. The load was transmitted from top to bottom of the stage using a polymer PMMA (Polymethyl methacrylate) sleeve. PMMA was used because it is essentially $\mathrm{X}$-ray transparent. The specimen was inserted from the top of the stage and was clamped between the actuator and the load cell. The stepper motor had a captive linear actuator capable of $8 \mu \mathrm{m}$ per step and a total stroke of $25 \mathrm{~mm}$. The load cell had a capacity of $500 \mathrm{~N}$. The load was applied to the specimen by automatic control of the actuator using feedback from the load cell. The fatigue tests were run at constant load amplitude. After a specified number of cycles were completed, the load was held constant at a value slightly lower than the maximum load and the sample was scanned. A slight overload was obtained in the higher $R$-ratio sample due to the difficulty in controlling the load. The location and magnitude of the overload was recorded and the appropriate change in damage was quantified.

From the obtained stack of reconstructed images, the SiC particles were segmented from the Al alloy matrix. Due to the similarity in gray scale between the center of a particle and the Al alloy matrix, a novel and semi-automatic segmentation algorithm known as Livewire ${ }^{\circledR}$ (Mimics, Materialise, Ann Arbor, MI) was used, and is described in detail elsewhere [29]. This algorithm takes advantage of the large gradient in grayscale at the interface between the particle and the matrix $[43,44]$. The crack was also segmented at various stages of growth using a grayscale thresholding tool and subsequent close visual comparison to the original tomography images for removal of anything falsely segmented as part of the crack, such as the dark silicon-rich inclusions. The segmented data was then exported to Avizo ${ }^{\circledR}$ Fire (Visualization Sciences Group, Burlington, MA) for 3D rendering and microstructural quantification. Selected volumes for each $R$-ratio were considered for 3D quantification. These volumes were selected such that the width was equal, the height encompassed the full crack throughout that width, and the length captured the full propagation of the crack. Videos were made for the high $R$-ratio sample to show crack growth, particle fracture, and crack-particle interaction throughout the in situ fatigue experiment in $4 \mathrm{D}$.

\section{Results and discussion}

The differences in fatigue crack growth damage at the tip of the crack, and the subsequent interactions between the crack and the SiC particles, at low and high $R$-ratio, are quite striking. A $2 \mathrm{D}$ comparison of the evolution of damage under a load ratio of $0.1(135 \mu \mathrm{m}$ 

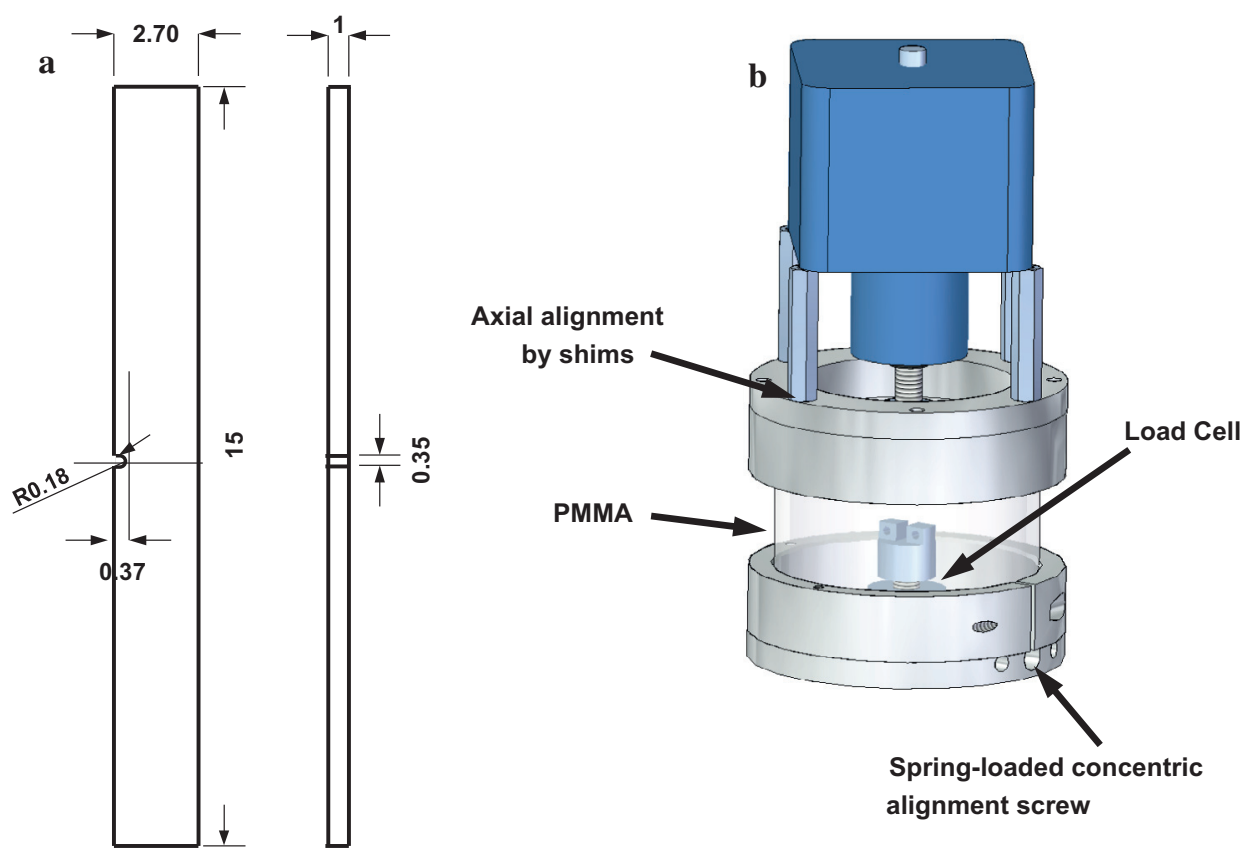

Fig. 1. (a) Single edge notch specimen used for in situ experiments (dimensions are in mm) and (b) in situ fatigue testing jig.

from the specimen surface) versus a load ratio of 0.6 (157 $\mu \mathrm{m}$ from the specimen surface) can be seen in Figs. 2 and 3, respectively. In Fig. 2(a), under the lower load ratio, very few of the particles in the area in front of the crack are visibly fractured. Fig. 2(b) shows that the crack proceeds in a nearly linear fashion until it reaches a particle, and is then deflected and goes around the particle. By the time the image in Fig. 2(c) was captured, the crack has passed by another particle and proceeded in a way so as to be in line with the path of the crack prior to deflecting around the first particle mentioned. In contrast, it can be seen in Fig. 3(a) that the sample under higher load ratio contains a number of fractured particles in the area ahead of the crack tip. Fig. 3(b) shows that several particles are fractured ahead of the crack, and that the crack path is tortuous so as to travel towards and through previously fractured particles. This comparison was found to be representative of the fatigue damage behavior throughout the respective samples, and was confirmed through quantification and 3D analysis.

The fracture of a particle ahead of the crack tip during high load ratio $(R=0.6)$ fatigue can be more clearly seen in Fig. 4, at a depth of $295 \mu \mathrm{m}$ from the specimen surface. Fig. 4(a) shows that the particle (circled) was not fractured when the experiment was paused for scanning after 7000 fatigue cycles. However, the particle had fractured by 8000 cycles (Fig. 4(b)) and the crack later passed through the same fractured particle, as shown in Fig. 4(c).

This method of tomography image comparison at specified intervals of fatigue cycling enables us to quantify the degree of particle fracture as a function of cumulative fatigue cycles. Similarly, the interaction of the crack with the particles, i.e., whether it passes through a fractured particle or by-passes a particle, can also be quantified. 10 evenly-spaced 2D slices, similar to those shown in Figs. 2-4, yet covering a much larger area to ensure all fractured particles could be seen, were selected from the image stacks and quantified for each sample at every instance of image collection. The results are shown in Figs. 5 and 6. Quantities in these figures represent the cumulative number of instances observed. In Fig. 5, the number of particles by-passed under low load ratio increases at nearly every interval of observation. The crack passed through fractured particles in relatively few cases, and none of those particles were observed to have fractured ahead of the crack tip in any image collected prior to 6700 cycles (corresponding to crack length of $1.32 \mathrm{~mm}$ ). This indicates that, for these earlier intervals of fatigue, when the crack passed through a fractured particle at low load ratio, that particle must have fractured at little to no distance in front of the crack tip. In contrast, a large number of particles were observed to have fractured ahead of the crack tip at high load ratio $(R=0.6)$ (Fig. 6). The corresponding trend shown by the number of particles through which the crack has passed relates to the aforementioned phenomenon of crack growth at high $R$-ratio; that the crack tends to pass through particles that have already been fractured ahead of the crack tip. Particle fracture ahead of the crack tip was exacerbated by two separate instances of overloading during the fatigue testing at high load ratio due to the problems in controlling the load: just prior to 6000 cycles, and again just prior to 8000 cycles. The impact of this overloading is clear in Fig. 6. The overloads were not very large, for example, with $\Delta K$ increasing from 4.5 to $4.9 \mathrm{MPa} \mathrm{m}^{1 / 2}$, and $K_{\max }$ increasing from 11.5 to
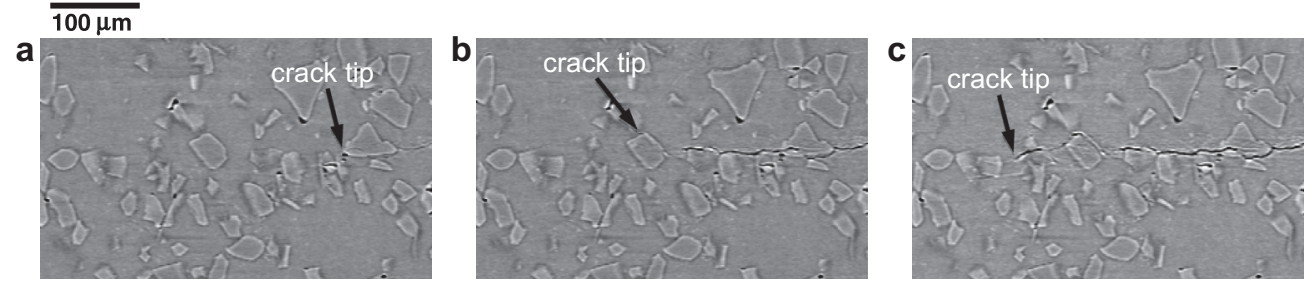

Fig. 2. Fatigue crack growth behavior at $135 \mu \mathrm{m}$ from specimen surface at $R=0.1$ after (a) 5700 , (b) 7400 and (c) 7900 fatigue cycles. Location of crack tip is indicated. 

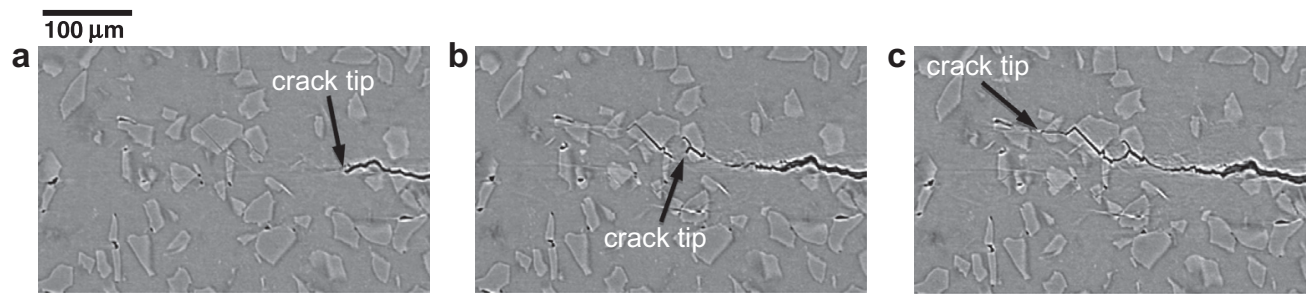

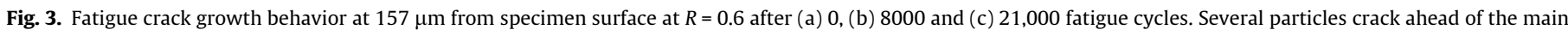
crack. Location of crack tip is indicated.
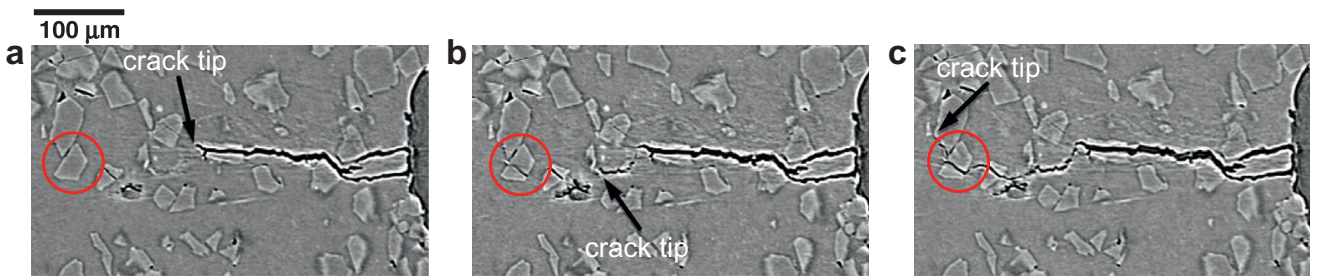

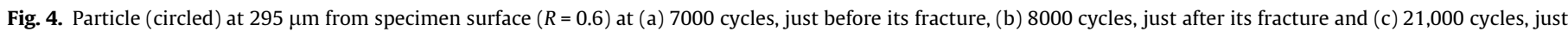
after crack passes through particle. Location of crack tip is indicated.

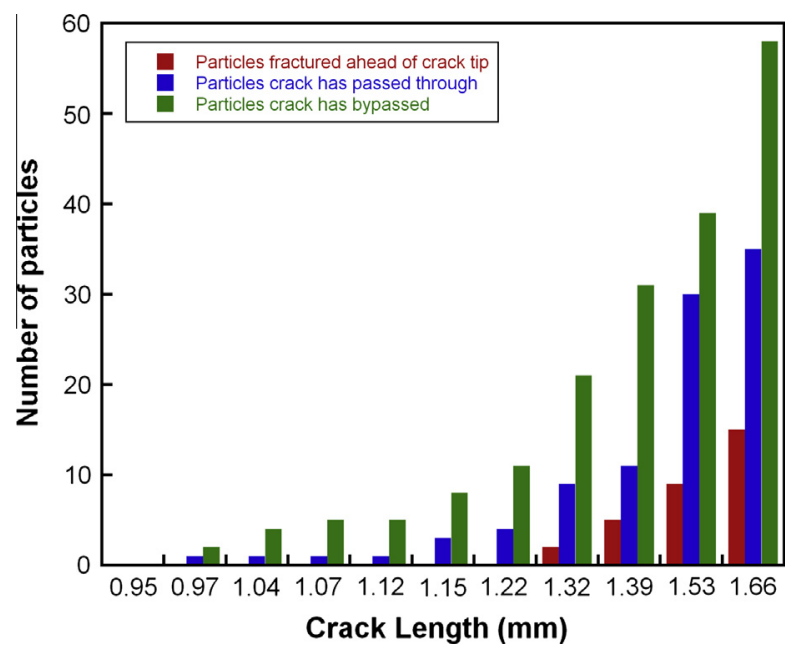

Fig. 5. Quantification of particle fracture and interaction with crack at $R=0.1$ as observed in 10 evenly-spaced slices.

$13 \mathrm{MPa} \mathrm{m}^{1 / 2}$. The stress intensity factor $(K)$ was calculated using the equations derived by Ahmad et al. [45] for single edge notched specimens. At both 6000 and 8000 cycles, the number of observed particles fractured increased sharply. Both instances were followed by plateaus, as the area affected by overload was larger than that affected during normal loading, so the crack tip must travel further before more new particles are fractured in the area in front of it, and no additional particles were fractured in the interim. The range of $d a / d N$ at which the investigations were conducted was $10^{-7}-6 \times 10^{-9} \mathrm{~m} /$ cycle. It is also interesting to note that after the overload, crack growth rates were similar to those observed just before the overload $\left(\sim 7.5 \times 10^{-9} \mathrm{~m} /\right.$ cycle $)$, indicating that overload did not cause fatigue crack growth retardation, whereas crack growth retardation has been observed following overload in unreinforced $\mathrm{Al}$ alloys. This can be attributed to the sudden increase in the number of fractured particle due to the damage produced by overloads, which facilitates the crack propagation. Zybell et al. [46] and Hubner et al. [47] also found no retardation in crack growth rate following overload $\left(K_{\max }\right.$ from $14 \mathrm{MPa} \mathrm{m}^{1 / 2}$ to $28 \mathrm{MPa} \mathrm{m}^{1 / 2}$ ) in nodular cast iron and they attributed this behavior

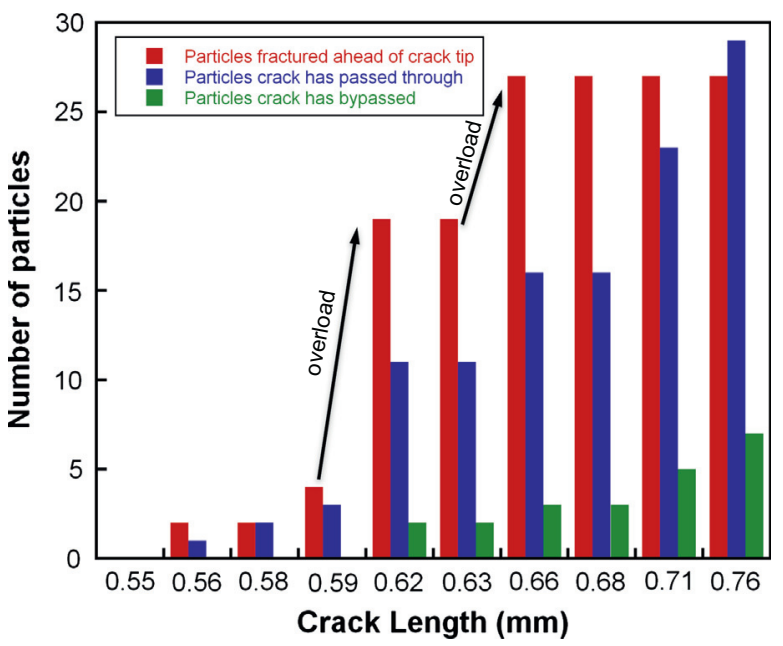

Fig. 6. Quantification of particle fracture and interaction with crack at $R=0.6$ as observed in 10 evenly-spaced slices. Overload occurs just before 6000 cycles and before 8000 cycles, as indicated.

to the debonding of graphite particles from the matrix due to the damage produced by the overload. In our case, damage took place by fracture of SiC particles ahead of the crack tip at high $K_{\max }$ (high $R$-ratio).

One of the hypotheses for crack growth in particle reinforced MMCs is that $K_{\max }$ controls the degree of particle fracture, and thus, the path of the fatigue crack $[39,48]$. The effect of $K_{\max }$ on particle fracture can be seen in Fig. 7. The cumulative number of particles fractured is divided by the crack length as a means to normalize the quantities for low and high $R$-ratio. The number of particles fractured over crack length during $R=0.1$ increases with $K_{\max }$, indicating the $K_{\max }$ controls degree of particle fracture. By comparing with Fig. 5, it can be seen that the particles are not fractured ahead of the crack tip (until crack length of $1.32 \mathrm{~mm}$ ), and particle primarily deflect around the particles. In the case of $R=0.6$, it is clear that particles are fractured ahead of the crack tip, even without the overload (until crack length of $0.59 \mathrm{~mm}$ in Fig. 6). The sudden increase in number of fractured particles can be explained by the instances of overload. The overload causes additional damage (additional 


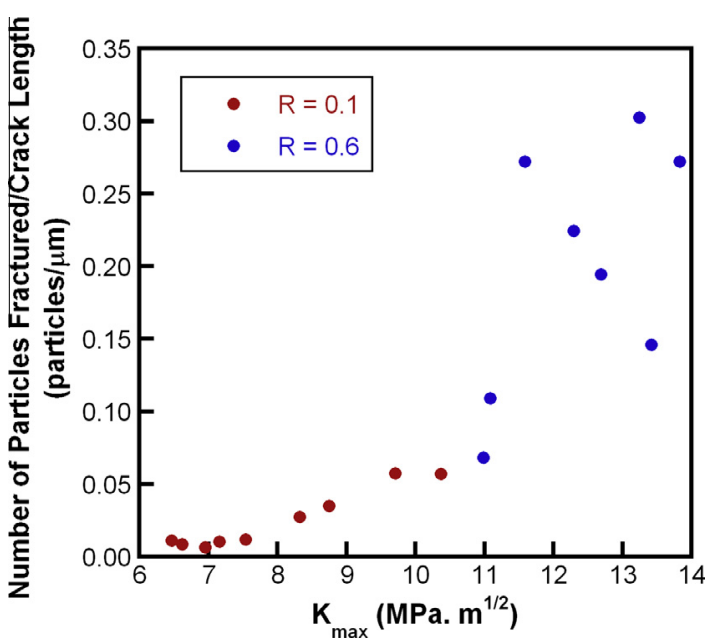

Fig. 7. Effect of $K_{\max }$ on particle fracture. Number of particles fractured increases with $K_{\max }$. Instances of decrease for $R=0.6$ are a result of overloading.

particle fracture). As aforementioned, crack growth immediately following overload does not cause additional particle fracture, but the crack length continues to increase. Because the cumulative number of fractured particles remains constant while crack length increases, the parameter of fractured particles divided by crack length decreases while $K_{\max }$ increases in the period following overload. Recently, Bacon et al. [48] performed experiments to understand the damage mechanisms during crack propagation in 316 stainless steel metal matrix composite reinforced with $25 \%$ titanium diboride. Based on the fracture surface observation, they also observed increase in particle fracture with an increase in $K_{\max }$ due to increase in monotonic plastic zone size. Furthermore, they observed that the particle fracture was seen only after a very high value of $\Delta K\left(\sim 13 \mathrm{MPa} \mathrm{m}^{1 / 2}\right)$ in the case of low $R$-ratio $(R=0.1)$, whereas, for higher $R$-ratios $(R=0.5)$, particle fracture was seen starting at low $\Delta K\left(\sim 6 \mathrm{MPa} \mathrm{m}^{1 / 2}\right)$. Shang et al. $[33,49]$ showed that in $\mathrm{Al}-\mathrm{SiC}$ composites at low $R$-ratio, the crack tends to bypass the particles at low $\Delta K$ and the extent of particle fracture increases with an increase in $\Delta K$, similar to what has been observed by Bacon et al., Chawla and Ganesh [39] showed that the number of fractured particles per unit area were higher in higher $R$-ratio than at lower $R$-ratio and that particles are fractured ahead of the crack tip in the case of higher $R$-ratios as a result of the larger plastic zone size due to high $K_{\max }$, however, the analysis was performed by observing only the fracture surface. In our study, the stress intensity factor range for $R=0.6$ was $4.2-5.7 \mathrm{MPa} \mathrm{m}^{1 / 2}$ and for $R=0.1$ was from 5.45 to $9.33 \mathrm{MPa} \mathrm{m}^{1 / 2}$. Observations from Figs. 5-7 confirm that for $R=0.1$, the occurrence of particle fracture ahead of the crack tip started only at higher values of $\Delta K\left(>7.5 \mathrm{MPa} \mathrm{m}^{1 / 2}\right.$ corresponding to crack length of $1.32 \mathrm{~mm}$ in Fig. 5), due to increase in value of $K_{\max }$. However, the occurrence of crack bypass around a particle remains the more dominant crack-particle interaction behavior. Below this value $\left(\Delta K \sim 7.5 \mathrm{MPa} \mathrm{m}^{1 / 2}\right)$ particles do not fracture ahead of the crack tip. However, in the case of $R=0.6$, the particles fracture ahead of the crack tip even at lower $\Delta K\left(4.2 \mathrm{MPa}-\mathrm{m}^{1 / 2}\right)$ due to high $K_{\text {max }}$.

It is known that the crack growth behavior at the interior of the specimen and at the surface may substantially differ. In particular, the surface is in a state of plane stress, while the interior is in plane strain, leading to a larger plastic zone size at the surface than at the interior [50]. The comparison of the damage on the surface to the interior has been shown in Fig. 8. The number of fractured particles is greater at the surface than at the interior in both samples, which can be attributed to the larger plastic zone/damage zone size on the surface than in the interior.

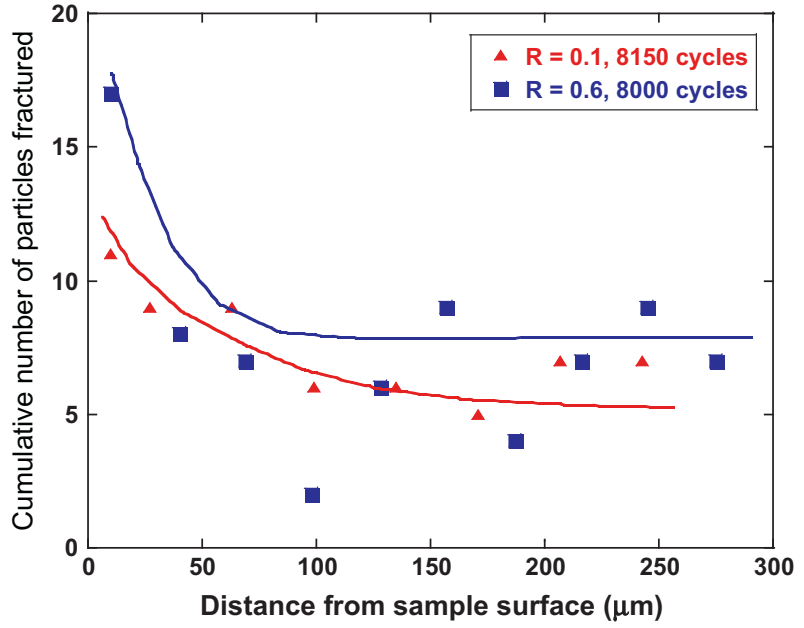

Fig. 8. Quantification of particle fracture showing different behavior at the surface than at the interior. The surface has greater number of fractured particles than at the interior.

Selected volumes for each $R$-ratio were segmented, as shown in Figs. 9 and 10. Particles that touch the crack, i.e., particles the crack either travelled through or bypassed, are shown in blue, while the remainder of the particles in the selected volume are shown in green. Figs. 9(a) and 10(a) show all particles in the selected volume along with the fully propagated crack, while Figs. 9(b) and 10(b) show only those particles with which the fatigue cracks interacted.

Each particle with which the crack interacted was visually examined in 3D to determine if the fatigue crack travelled through that particle or if it instead bypassed the particle. A statistical summary of the quantified interactions between particles and fatigue crack is shown in Table 1 for both 2D and 3D analysis methods under both low and high load ratios. The statistics show that the fatigue crack has a tendency to bypass particles under low load ratio. In stark contrast, at high load ratio the particles fracture ahead of the crack, due to a large damage zone from the higher $K_{\max }$ contribution, and the fatigue crack passes through upwards of 4 out of 5 particles in its path, on average. For low load ratio, the difference in results between methods is less than $4 \%$, while high load ratio results differ by less than $9 \%$.

Further 3D analysis was performed on crack growth under high load ratio. Approximately 300 particles were segmented in a region in front of a $380 \mu \mathrm{m}$ wide section of the crack. Care was taken to ensure that all particles near the fully propagated crack in that region were segmented by comparison with images collected at 21,000 cycles. The fatigue crack was also segmented at each interval during which fatigue was paused for scanning. Using the 3D segmented data, together with reference to the image stacks, particles were separated based on the following criteria: (a) the particle interacts with the crack, (b) the particle fractures, (c) during which interval particle fracture occurs and (d) during which interval the crack passes though the particle. From this, it is possible to visualize when particles fracture and when the crack travels through those particles during fatigue crack growth. A video was made to aid in this visualization, from which select still images were taken and shown in Fig. 11. To make visualization clear, the quantity of particles shown is limited. Therefore, only those particles which are fractured and through which the particle ultimately travels are shown, with all other particles hidden. Particles appear in green when they have been fractured during that interval. A particle then changes to blue once the crack has passed through it. Fig. 11(a) shows the crack and fractured particles at the beginning of the fatigue experiment, where the crack has not passed through any particles and fractured particles are a result of pre-cracking or processing. In Fig. 11(b), the 

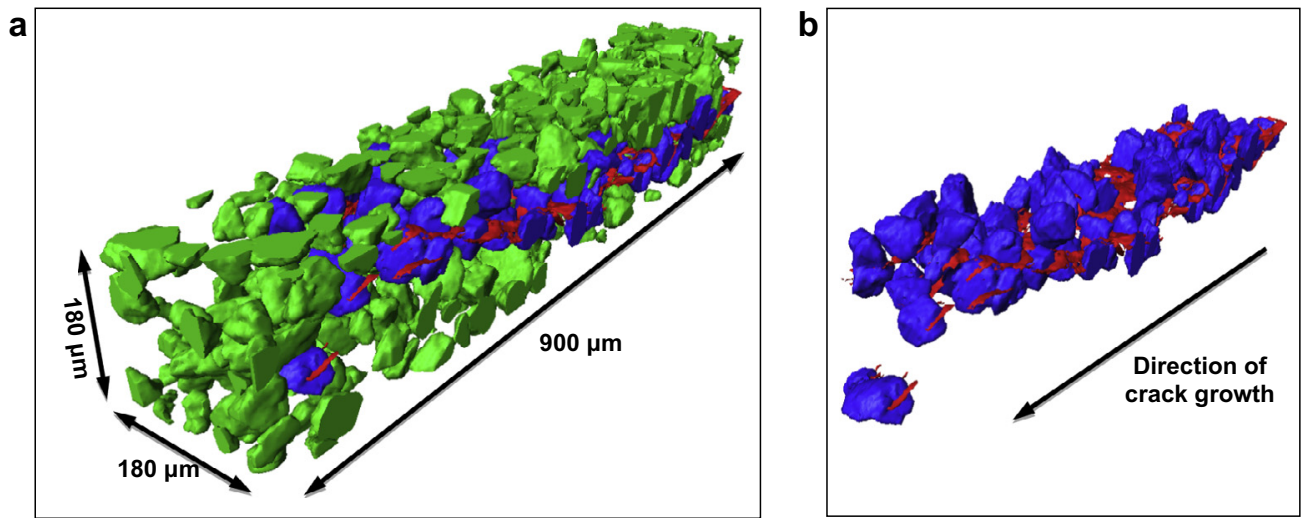

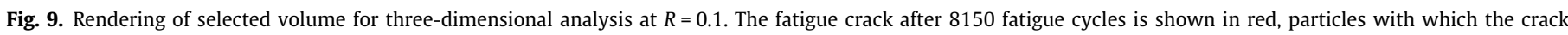

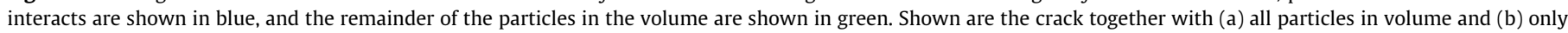
those particles with which crack interacts. (For interpretation of the references to colour in this figure legend, the reader is referred to the web version of this article.)
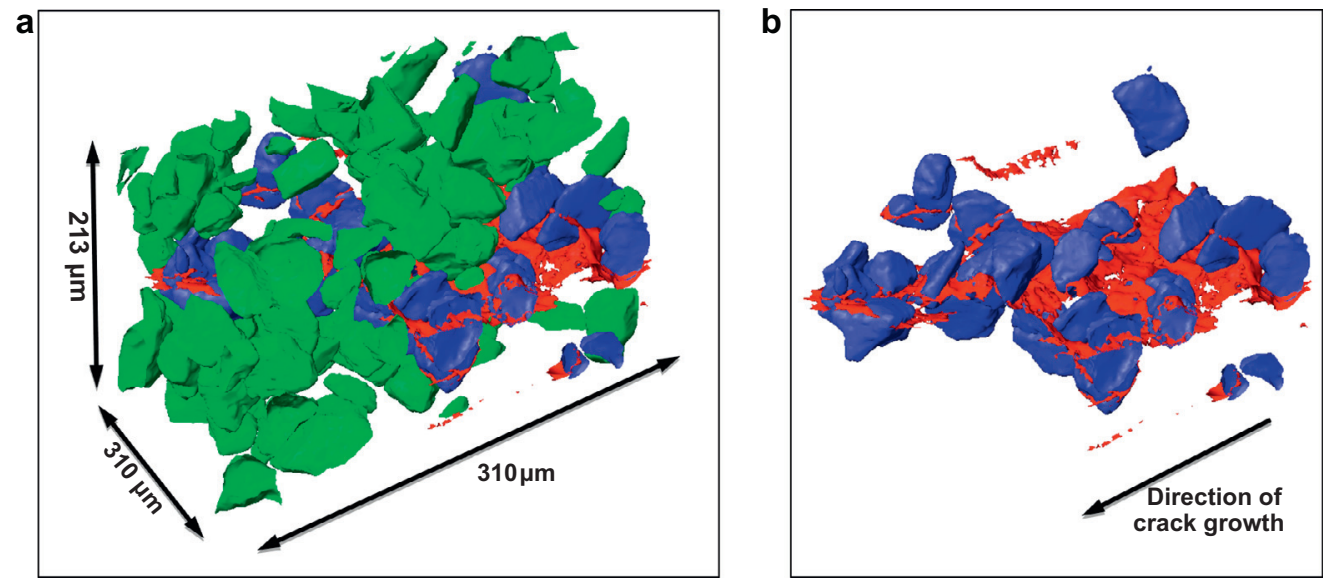

Fig. 10. Rendering of selected volume for three-dimensional analysis at $R=0.6$. The fatigue crack after 21,000 fatigue cycles is shown in red, particles with which the crack interacts are shown in blue, and the remainder of the particles in the volume are shown in green. Shown are the crack together with (a) all particles in volume and (b) only those particles with which crack interacts. (For interpretation of the references to colour in this figure legend, the reader is referred to the web version of this article.)

Table 1

Statistical summary for both two- and three-dimensional analysis techniques.

\begin{tabular}{|c|c|c|c|c|}
\hline \multirow[t]{2}{*}{ Analysis Method } & \multicolumn{2}{|c|}{$R=0.1$} & \multicolumn{2}{|c|}{$R=0.6$} \\
\hline & $2 \mathrm{D}$ & $3 \mathrm{D}$ & $2 \mathrm{D}$ & $3 \mathrm{D}$ \\
\hline Total number of observed particles with which crack interacts during fatigue crack growth & 93 & 98 & 36 & 29 \\
\hline$\%$ Particles crack passes through & 37.6 & 33.7 & 80.6 & 89.7 \\
\hline$\%$ Particles crack bypasses & 62.4 & 66.3 & 19.4 & 10.3 \\
\hline$\%$ Particles through which crack passes that fractured ahead of crack tip & 28.6 & 9.1 & 89.7 & 84.6 \\
\hline
\end{tabular}
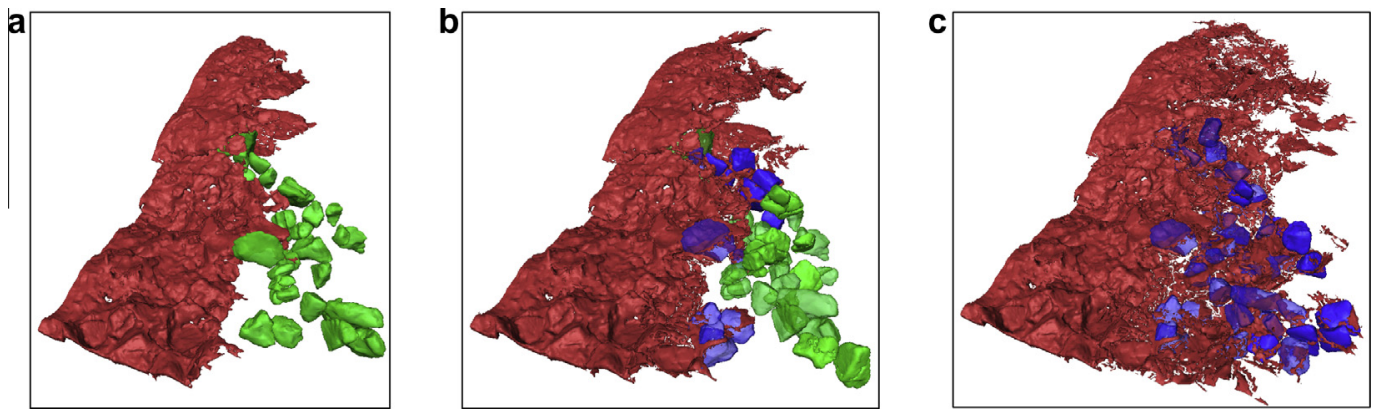

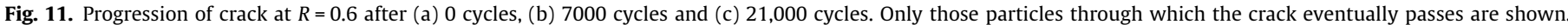

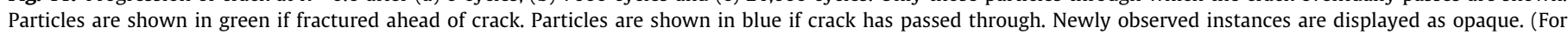
interpretation of the references to colour in this figure legend, the reader is referred to the web version of this article.) 
sample has been fatigued for 7000 cycles, and the crack has propagated through a number of particles, with additional particles having been fractured in front of the crack tip. Fig. 11(c) shows the fully propagated crack, which has passed through all particles shown, as this was the criterion for selection of the visible particles. Use of the video to show the crack growth and particle fracture interdependence in $4 \mathrm{D}$ is valuable in understanding the phenomena of particle fracture at an appreciable distance in front of the crack tip as well as the influence of those fractured particles on the path followed by the crack during fatigue.

\section{Conclusions}

In situ X-ray synchrotron tomography was used to study the fatigue behavior of $\mathrm{SiC}$ particle-reinforced $2080 \mathrm{Al}$ alloy matrix in $4 \mathrm{D}$ at low and high $R$-ratios. The following conclusions can be drawn from this work.

1. For $R$-ratio of 0.1 , particles do not fracture at an appreciable distance ahead of the crack tip at low $\Delta K$. Because of this, the crack has the tendency to follow a path around particles, bypassing them. At higher $\Delta K$, particles tend to fracture ahead of the crack tip due to high $K_{\max }$

2. For $R$-ratio of 0.6 , fracture of particles ahead of the crack tip is common even at the low $\Delta K$ due to large $K_{\max }$. Once particles have fractured in front of the crack tip, subsequent crack growth occurs in the direction of those fractured particles, effectively passing through them. Thus, the static component of fracture, $K_{\max }$, controls fatigue crack growth by causing the $\mathrm{SiC}$ particles to fracture ahead of the crack tip.

3. Current segmentation and 3D rendering software enables true 4D visualization of fatigue crack growth through the creation of videos, aiding in the understanding of fatigue damage of MMCs, particularly particle-crack interactions.

\section{Acknowledgement}

Use of the Advanced Photon Source was supported by the U.S. Department of Energy, Office of Science, Office of Basic Energy Sciences, under Contract No. DE-AC02-06CH11357.

\section{References}

[1] Chawla KK, Chawla N. Metal matrix composites. New York: Springer Verlag; 2006

[2] Chawla N, Shen Y. Mechanical behavior of particle reinforced metal matrix composites. Adv Eng Mater 2001;3:357-70.

[3] Chawla N, Allison JE. Fatigue of particle reinforced materials. In: Buschow KH] Cahn RW, Flemings MC, Ilschner B, Kramer EJ, Mahajan S, Veyssière P, editors. Encyclopedia of materials: science and technology (second edition). Oxford: Elsevier; 2001. p. 2967-71.

[4] Ganesh V, Chawla N. Effect of reinforcement-particle-orientation anisotropy on the tensile and fatigue behavior of metal-matrix composites. Metall Mater Trans A 2004;35:53-61.

[5] Chawla N, Jones J, Andres C, Allison J. Effect of SiC volume fraction and particle size on the fatigue resistance of a $2080 \mathrm{Al} / \mathrm{SiC}$ p composite. Metall Mater Tran A 1998;29:2843-54.

[6] Chawla N, Andres C, Jones J, Allison J. Cyclic stress-strain behavior of particle reinforced metal matrix composites. Scr Mater 1998:38:1595-600.

[7] Chawla N, Andes C, Davis L, Allison J, Jones J. The interactive role of inclusions and $\mathrm{SiC}$ reinforcement on the high-cycle fatigue resistance of particle reinforced metal matrix composites. Metall Mater Trans A 2000;31:951-7.

[8] Chawla N, Habel U, Shen Y, Andres C, Jones J, Allison J. The effect of matrix microstructure on the tensile and fatigue behavior of $\mathrm{SiC}$ particle-reinforced 2080 Al matrix composites. Metall Mater Trans A 2000;31:531-40.

[9] Maire E, Buffière J, Salvo L, Blandin J, Ludwig W, Letang J. On the application of $\mathrm{X}$-ray microtomography in the field of materials science. Adv Eng Mater 2001;3:539-46.

[10] Salvo L, Cloetens P, Maire E, Zabler S, Blandin J, Buffière J, et al. X-ray microtomography an attractive characterisation technique in materials science. Nuc Instrum Methods Phys Res, Sect B 2003;200:273-86.
[11] Sidhu R, Chawla N. Three-dimensional microstructure characterization of $\mathrm{Ag}<\mathrm{sub}>3 \mathrm{Sn}$ intermetallics in Sn-rich solder by serial sectioning. Mater Charact 2004;52:225-30.

[12] Dudek M, Chawla N. Three-dimensional (3D) microstructure visualization of $\mathrm{LaSn}_{3}$ intermetallics in a novel Sn-rich rare-earth-containing solder. Mater Charact 2008;59:1364-8.

[13] Kubis A, Shiflet G, Hull R, Dunn D. Focused ion-beam tomography. Metall Mater Trans A 2004;35:1935-43.

[14] Singh D, Chawla N, Shen Y. Focused ion beam (FIB) tomography of nanoindentation damage in nanoscale metal/ceramic multilayers. Mater Charact 2010;61:481-8.

[15] Lasagni F, Lasagni A, Marks E, Holzapfel C, Mücklich F, Degischer H. Threedimensional characterization of 'as-cast' and solution-treated AlSi12 (Sr) alloys by high-resolution FIB tomography. Acta Mater 2007;55:3875-82.

[16] Buffiere J, Maire E, Adrien J, Masse J, Boller E. In situ experiments with x ray tomography: an attractive tool for experimental mechanics. Exp Mech 2010;50:289-305.

[17] Stock S. X-ray microtomography of materials. Int Mater Rev 1999;44:141-64.

[18] Beckmann F, Grupp R, Haibel A, Huppmann M, Nöthe M, Pyzalla A, et al. In-situ synchrotron X-ray microtomography studies of microstructure and damage evolution in engineering materials. Adv Eng Mater 2007;9:939-50.

[19] Withers PJ, Preuss M. Fatigue and damage in structural materials studied by Xray tomography. Annu Rev Mater Res 2012:42:81-103.

[20] Dudek M, Hunter L, Kranz S, Williams J, Lau S, Chawla N. Three-dimensional (3D) visualization of reflow porosity and modeling of deformation in Pb-free solder joints. Mater Charact 2010;61:433-9.

[21] Chawla N, Williams JJ, Deng X, McClimon C, Hunter L, Lau S. Threedimensional characterization and modeling of porosity in PM steels. Int J Powder Metall 2009;45:19-27.

[22] Babout L, Maire E, Buffière J, Fougeres R. Characterization by X-ray computed tomography of decohesion, porosity growth and coalescence in model metal matrix composites. Acta Mater 2001;49:2055-63.

[23] Borbély A, Csikor F, Zabler S, Cloetens P, Biermann H. Three-dimensional characterization of the microstructure of a metal-matrix composite by holotomography. Mater Sci Eng, A 2004;367:40-50.

[24] Kenesei P, Biermann H, Borbély A. Structure-property relationship in particle reinforced metal-matrix composites based on holotomography. Scr Mater 2005;53:787-91.

[25] de Andrade Silva F, Williams JJ, Müller BR, Hentschel MP, Portella PD, Chawla N. Three-dimensional microstructure visualization of porosity and Fe-rich inclusions in SiC particle-reinforced Al alloy matrix composites by X-Ray synchrotron tomography. Metall Mater Trans A 2010;41:2121-8.

[26] Weck A, Wilkinson D, Maire E, Toda H. Visualization by X-ray tomography of void growth and coalescence leading to fracture in model materials. Acta Mater 2008;56:2919-28.

[27] Toda H, Yamamoto S, Kobayashi M, Uesugi K, Zhang H. Direct measurement procedure for three-dimensional local crack driving force using synchrotron Xray microtomography. Acta Mater 2008;56:6027-39.

[28] Singh SS, Williams JJ, Xiao X, De Carlo F, Chawla N. In situ three dimentional (3D) X-ray synchrotron tomography of corrosion fatigue in Al7075 alloy. Fatigue Mater II: Adv Emergences Understanding 2012:17-25.

[29] Williams J, Flom Z, Amell A, Chawla N, Xiao X, De Carlo F. Damage evolution in $\mathrm{SiC}$ particle reinforced $\mathrm{Al}$ alloy matrix composites by X-ray synchrotron tomography. Acta Mater 2010;58:6194-205.

[30] Williams J, Chapman N, Jakkali V, Tanna V, Chawla N, Xiao X, et al. Characterization of damage evolution in $\mathrm{SiC}$ particle reinforced Al alloy matrix composites by in-situ X-ray synchrotron tomography. Metall Mater Trans A 2011;42:2999-3005.

[31] Zhang H, Toda H, Qu P, Sakaguchi Y, Kobayashi M, Uesugi K, et al. Threedimensional fatigue crack growth behavior in an aluminum alloy investigated with in situ high-resolution synchrotron X-ray microtomography. Acta Mater 2009;57:3287-300

[32] Schöbel M, Altendorfer W, Degischer H, Vaucher S, Buslaps T, Michiel MD, et al. Internal stresses and voids in $\mathrm{SiC}$ particle reinforced aluminum composites for heat sink applications. Compos Sci Technol 2011;71:724-33.

[33] Shang JK, Yu W, Ritchie R. Role of silicon carbide particles in fatigue crack growth in SiC-particulate-reinforced aluminum alloy composites. Mater Sci Eng, A 1988;102:181-92.

[34] Kumai S, King JE, Knott JF. Short and long fatigue crack growth in a SiC reinforced aluminium alloy. Fatigue Fract Eng Mater Struct 1990:13:511-24.

[35] Schmidt R, Paris P. Progress in flaw growth and fracture toughness testing. ASTM STP 1973;536:79-94.

[36] Liaw P, Lea T, Logsdon W. Near-threshold fatigue crack growth behavior in metals. Acta Metall 1983;31:1581-7.

[37] Zinsser Jr W, Lewandowski J. Effects of R-ratio on the fatigue crack growth of $\mathrm{Nb}-\mathrm{Si}$ (ss) and $\mathrm{Nb}-10 \mathrm{Si}$ in situ composites. Metall Mater Trans A 1998;29:1749-57.

[38] Hudson CM, Scardina JT. Effect of stress ratio on fatigue-crack growth in 7075T6 aluminum-alloy sheet. Eng Fract Mech 1969;1:429-46.

[39] Chawla N, Ganesh V. Fatigue crack growth of SiC particle reinforced metal matrix composites. Int J Fatigue 2010;32:856-63.

[40] De Carlo F, Tieman B. High-throughput X-ray microtomography system at the advanced photon source beamline 2-BM. SPIE 2004;5535:644-51.

[41] De Carlo F, Albee P, Chu YS, Mancini DC, Tieman B, Wang SY. High-throughput real-time X-ray microtomography at the advanced photon source. SPIE 2002;4503:1-13. 
[42] Peele A, De Carlo F, McMahon P, Dhal B, Nugent K. X-ray phase contrast tomography with a bending magnet source. Rev Sci Instrum 2005;76. 083707 083707-5.

[43] Padilla E, Jakkali V, Jiang L, Chawla N. Quantifying the effect of porosity on the evolution of deformation and damage in Sn-based solder joints by X-ray microtomography and microstructure-based finite element modeling. Acta Mater 2012;60:4017-26.

[44] Padilla E, Chawla N, Silva L, dos Santos V, Paciornik S. Image analysis of cracks in the weld metal of a wet welded steel joint by three dimensional (3D) X-ray microtomography. Mater Charact 2013;83:139-44.

[45] Ahmad J, Papaspyropoulos V, Hopper AT. Elastic-plastic analysis of edgenotched panels subjected to fixed grip loading. Eng Fract Mech 1991;38: 283-94.
[46] Zybell L, Chaves H, Kuna M, Mottitschka T, Pusch G, Biermann H. Optical in situ investigations of overload effects during fatigue crack growth in nodular cast iron. Eng Fract Mech 2012;95:45-56.

[47] Hubner P, Schlosser H, Pusch G, Biermann H. Load history effects in ductile cast iron for wind turbine components. Int J Fatigue 2007;29:1788-96.

[48] Bacon DH, Edwards L, Moffatt JE, Fitzpatrick ME. Fatigue and fracture of a 316 stainless steel metal matrix composite reinforced with $25 \%$ titanium diboride. Int J Fatigue 2013;48:39-47.

[49] Shang JK, Ritchie RO. On the particle-size dependence of fatigue-crack propagation thresholds in SiC-particulate-reinforced aluminum-alloy composites: role of crack closure and crack trapping. Acta Metall 1989;37(8):2261-78.

[50] Meyers M, Chawla KK. Mechanical behavior of materials. 2nd ed. Cambridge University Press; 2008. 